\section{كالية الهند
College of Engineeri \\ INFLUENCE OF WATER TABLE FLUCTUATION ON NATURAL SOURCE ZONE DEPLETION IN HYDROCARBON CONTAMINATED SUBSURFACE ENVIRONMENTS}

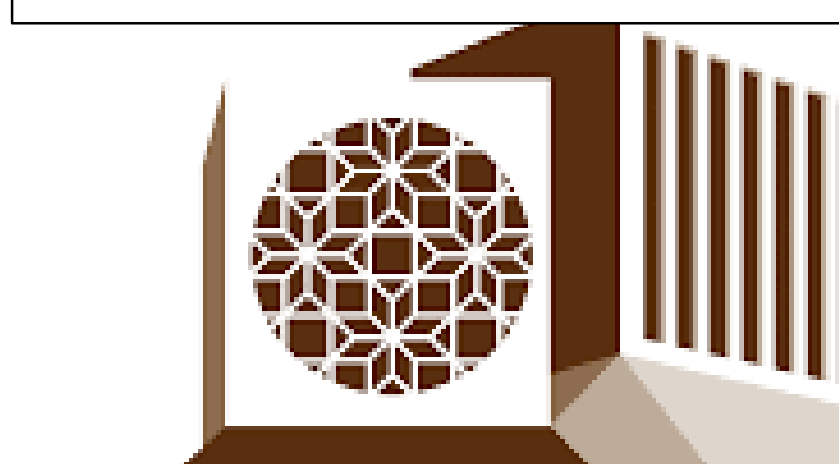

حـامعة قطر

QATAR UNIVERSIT: ${ }^{1}$ Department of Civil and Architectural Engineering, Qatar University, Doha, Qatar

${ }^{2}$ Ecohydrology Research Group, Department of Earth and Environmental Sciences, University of Waterloo, Waterloo, Canada
Reem Elfatih Ismail ${ }^{1,}$, Saeid Shafieiyoun ${ }^{1}$, Riyadh I. Al-Raoush ${ }^{1}$, Fereidoun Rezanezhad ${ }^{2}$, and Philippe Van Cappellen ${ }^{2}$

NATERLOO

\section{Background and Hypothesis}

Accidental spills of petroleum hydrocarbons (PHCs) are common source of soil and groundwater contamination in coastal environments that distribute in the subsurface systems as a nonaqueous phase liquid (NAPL)

Natural source zone depletion (NSZD) processes (including dissolution, volatilization, and biodegradation) and smearing due to water table fluctuations.

The water table fluctuation enhances the mass transfer of oxygen from the atmosphere to the groundwater which results in spatial gradient as well as temporal variation in local redox condition

We hypnosis that water table fluctuation under sulfate reducing bacteria will enhances the biodegradation of Toluene and biodegradation of Toluene and
Naphthalene compared to non fluctuating water table.

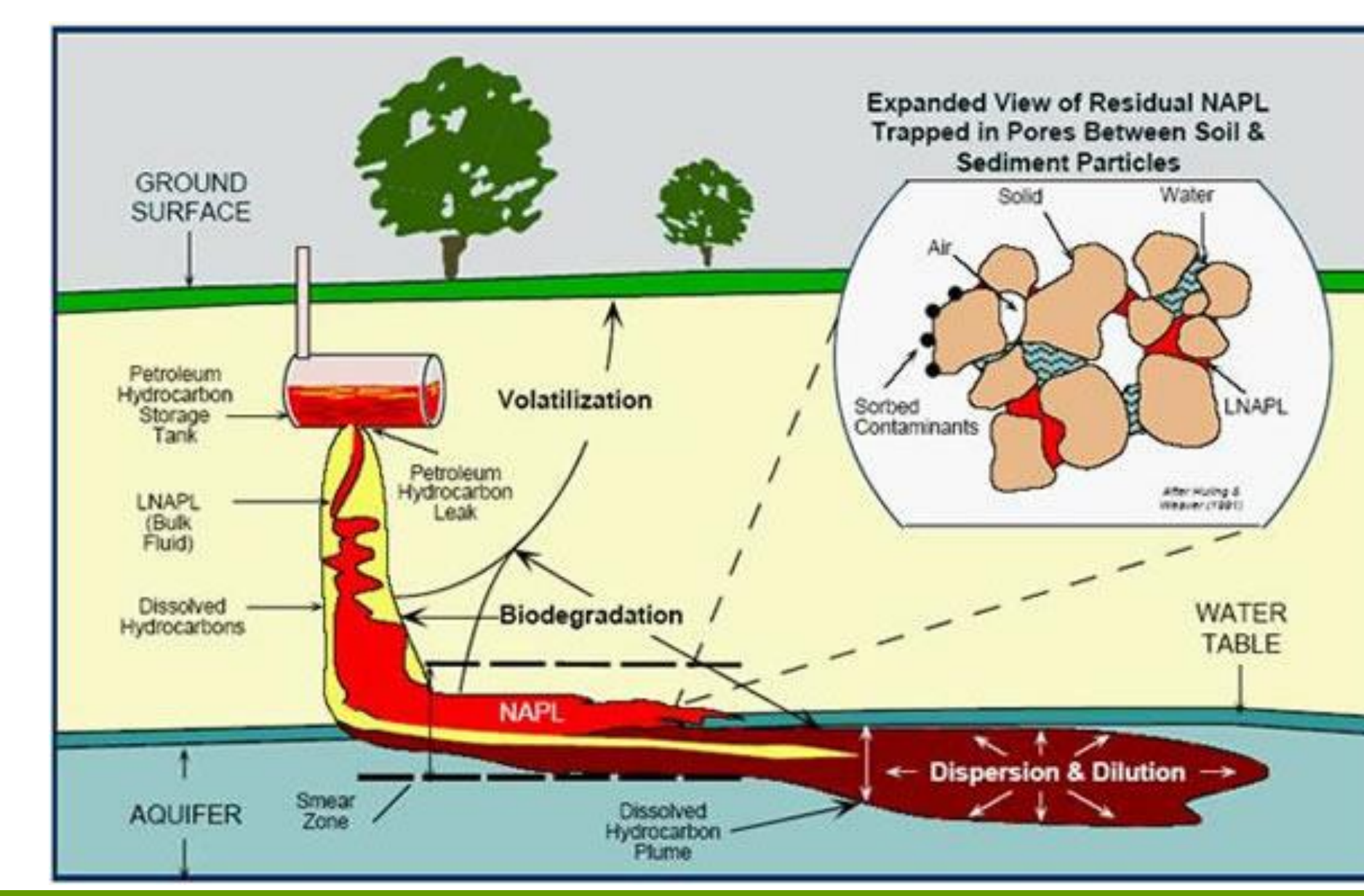

\section{Experimental Methodology}

An experiment of two columns operated under static condition, and

\section{Soil Preparation:}

$5 \mathrm{~kg}$ of uncontaminated soil was used for each column after removing Large size particles. $25 \%$ of the soil was taken and spiked by toluene and Naphthalene and mixed gently to provide a homogenized spiked soil sample.

Synthetic groundwater: Prepared by argon-purged deoxygenatec water (DO $<0.8 \mathrm{mg}^{-1} \mathrm{~L}$ ) based on groundwater analyses containing background nutrients.

$\square$ Two static columns connected tc one equilibrium column

columns were always saturated

$\square$ Two fluctuating columns, each one was connected to one equilibrium water column. They were fluctuating between top and $-40 \mathrm{~cm}$.

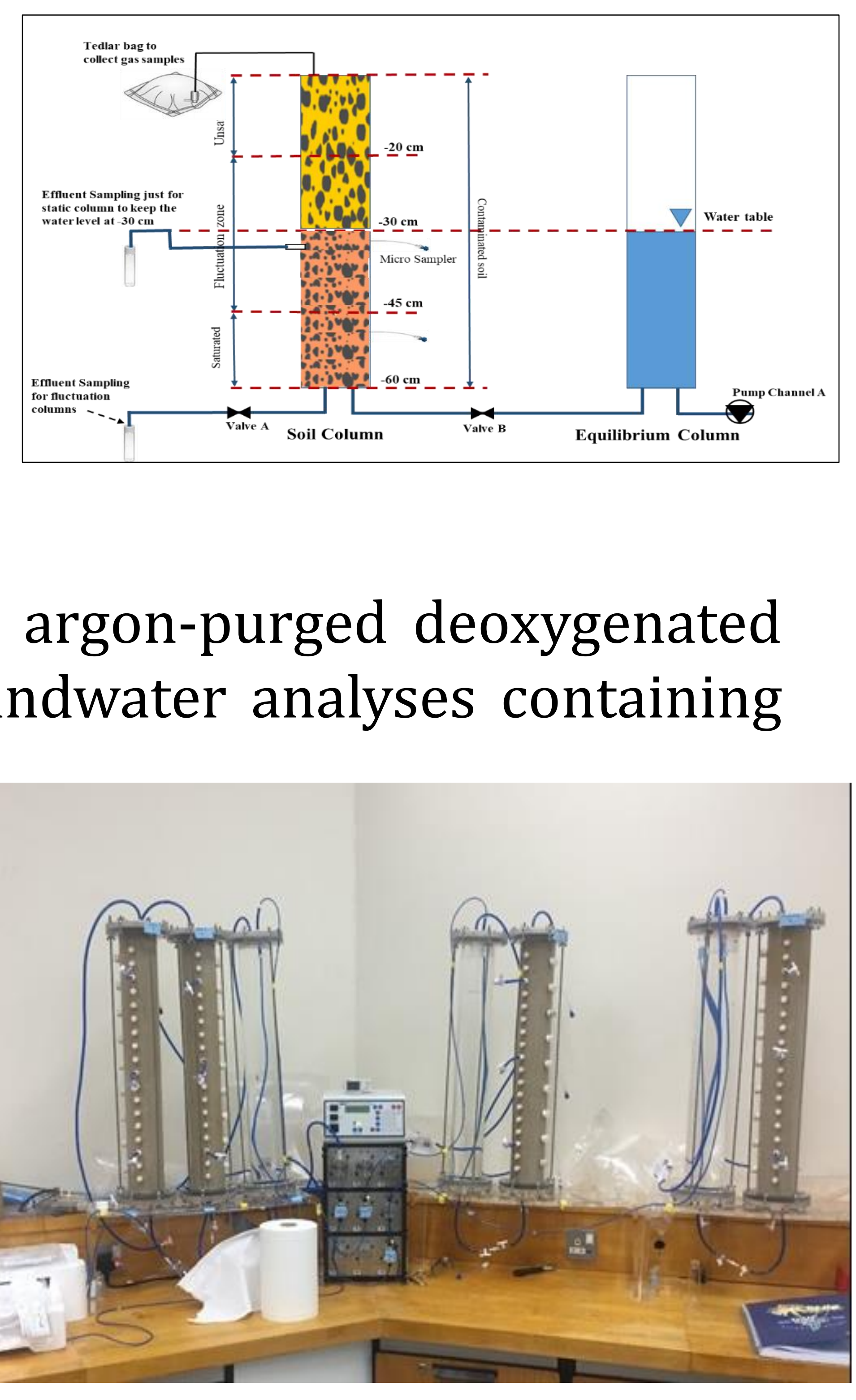

For fluctuating columns, Each week one drainage-saturation cycle $\square$ Two effluent aqueous samples collected each week at -30 and -50 port $\square$ Analysis include pH, DO, EC, ORP, DOC, DIC $\square$ sulfate/nitrate concentration

Organic concentration $n$ effluent samples (GC)

Soil initial \& final organic concentration (GC)

\section{Field Site and Soil Characterizations}

The soil was a sand with the texture class of sabkhas and saline beach sandy soils. It had elevated concentrations of soluble calcium, sodium, sulfur, chloride and sulfate.
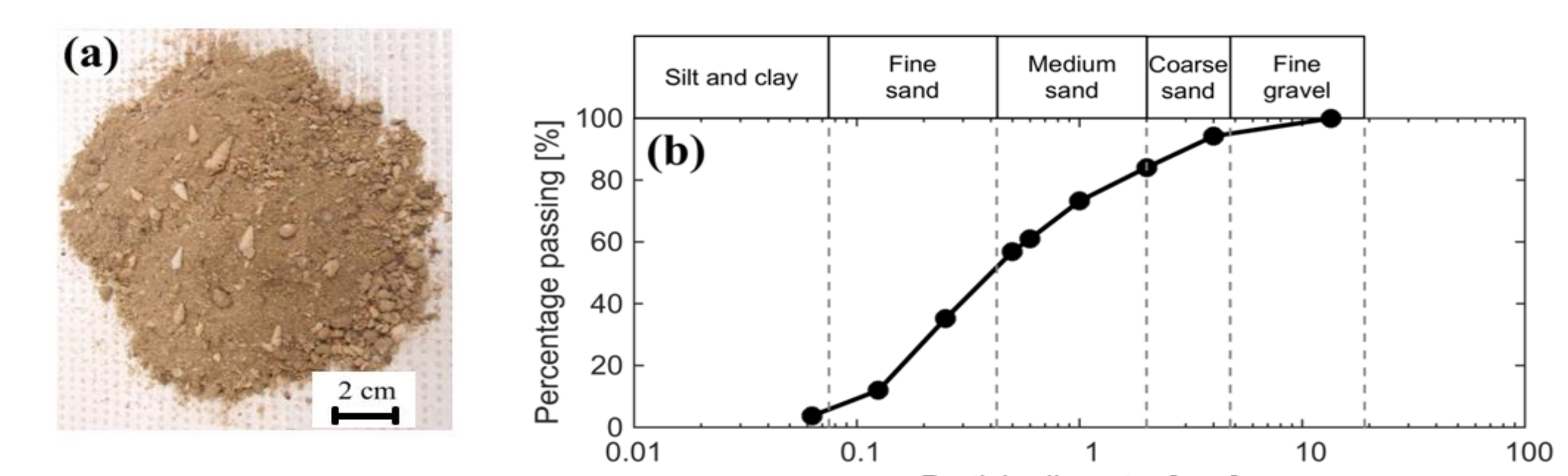

(a) Photograph of the soil and (b) the particle size distribution including seashells and using the Unified Soil Classification System (USCS).

\section{Objectives}

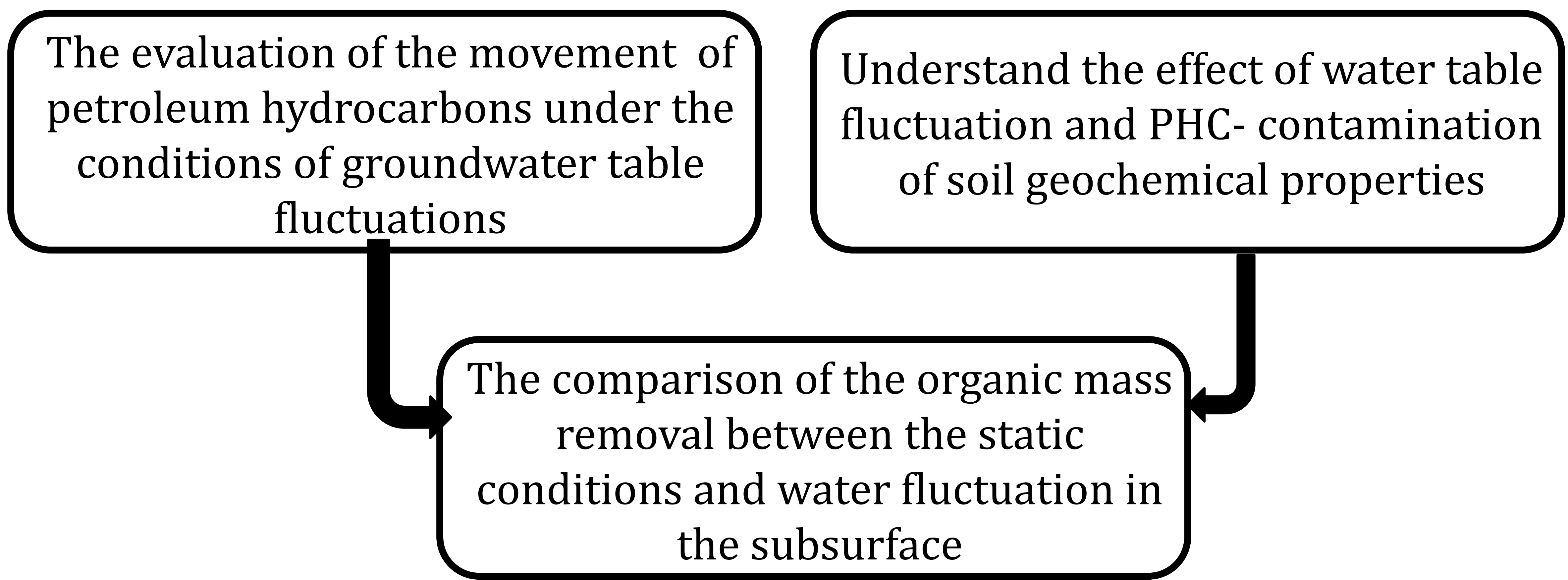

\section{Results}

The aerobic and anaerobic degradation of PHCs under static and water table fluctuations
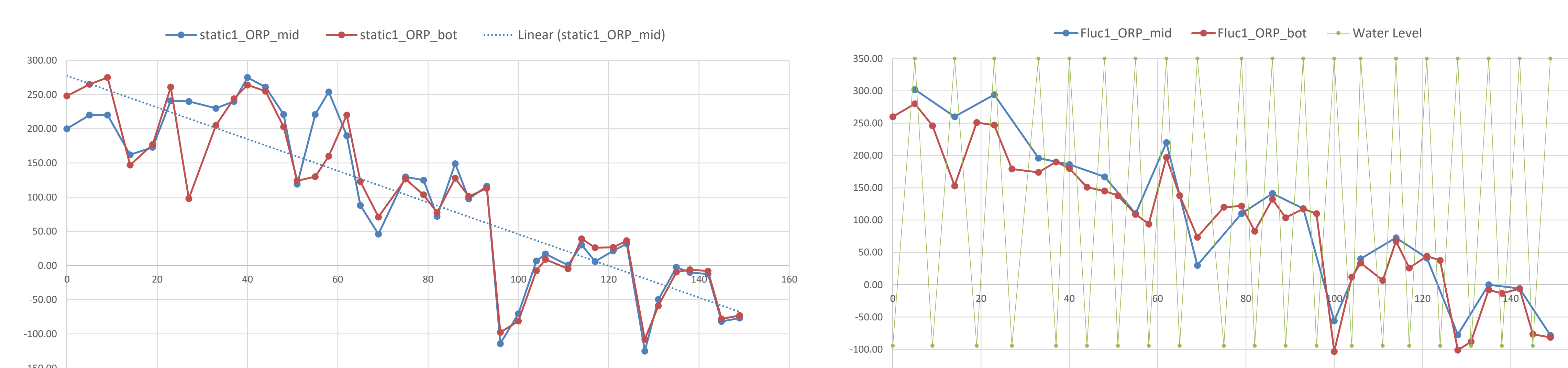

Left:

Pore water ORP values were $\sim 250 \mathrm{mV}$ and gradually decreased to $<100 \mathrm{mV}$ after 65 days indicating the development of reducing conditions and enhancement of anaerobic microbial community. Reducing condition was more significant in the stable water table columns.

Reducing condition during the drainage periods in the fluctuating water table columns is clear, while during the water rise oxidizing condition gradually changed to reducing conditions. Sodium sulfite was added as an important oxygen scavenger after 95 days, DO decreased very fast during water rise and ORP at both depths in all columns suddenly dropped to $-100 \mathrm{mV}$ and fluctuated in the range of -50 to $-100 \mathrm{mV}$ until the end of experimental period.

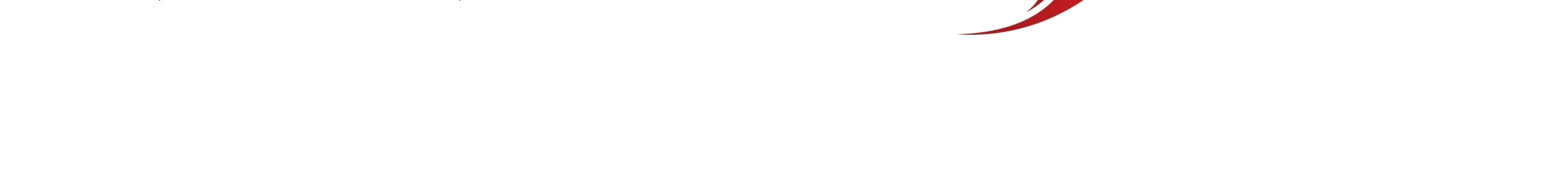

Chaires d'excellence
en recherche du Canada 